\title{
Participação social na conquista das políticas de saúde para mulheres no Brasil
}

\author{
Social participation in the achievement of health policies \\ to women in Brazil
}

Ana M aria Costa ${ }^{1}$

${ }^{1}$ Departamento deA poio à Gestão Participativa, SGEP, M inisterio da Saúde. SAFS Sul Quadra 2,Lotes 5 e6, Edificio Premium, Bloco F/ 303. 70070-600 Brasilia DF. ana.costa@saude.gov.br
Abstract This article analyzes the evolution of the participatory process in women's movements, especially those related to feminism, in the elaboration of health care policies to women in Brazil, from the 1970s until the present time. For this purpose, it is based on bibliography and on documentary analysis. The article determines the collaboration character that predominated in the beginning of the feminist movements' relations with State institutions, and their recent actions regarding institutionalized instances of social participation and control. It further underlines some changes in the polit$i$ cal activism of these movements, formerly advocating comprehensive health care to women and approaching the complexity of the broad demands and needs, and subsequently shifting to the defense of a focused acting, essentially when it comes to reproductive rights matters. Parallel to the acknowledgement of several achievements, the author emphasizes the necessity of disseminating the debate over women's health care in every space available for dialogue between the Government and the civil society in order to re-politicize this debate and to strengthen women's demands.

Key words Women's health care, Social participation, Participatory governance in women's health
Resumo Esseartigo analisa a evolução, a partir dos anos setenta, do processo participativo dos movimentos de mulheres, especialmente aquel es identificados com o feminismo, articulado à construção de políticas para a saúde das mulheres no Brasil. Para isso, se apóia na bibliografia e análise documental. I dentifica o caráter inicial colaboracionista quepredominou na relação dos movi mentos feministas com as instituições do Estado e sua recente atuação nas instâncias institucionalizadas de participação econtrole social. Assinala ainda mudanças de eixos de luta desses movimentos, antes defensores da saúde integral das mulheres e abordando toda a complexidade de suas amplas demandas e necessidades, para uma atuação focalizada, essencialmentevoltada aos direitos reprodutivos. A o lado dos numerosos avanços identificados, a autora ressalta a necessidade de disseminação do debate sobre o tema da saúde das mulheres em todos os espaços de interlocução entre governo e sociedade civil, repolitizando este debatee fortalecendo as demandas das mulheres. Palavras-chave Saúde da mulher, Participação social, Gestão participativa em saúde das mulheres 


\section{Panorama econtextos}

Todas as iniciativas do M inistério da Saúde relacionadas ao controle da natalidade nos anos setenta sofreram a oposição de diversos e difusos setores, desde os movimentos à esquerda como também os mais conservadores, incluindo a Igreja Católica. 0 movimento sanitário foi um dos importantes núcleos de resistência à implantação, no país, de programas de controle demográfico eparte desse movimento subsi diou a sustentação técnica e política conferida ao Programa de Assistência Integral à Saúde da Mulher (PAISM) concebido em 1983. Posteriormente, foram se definindo alianças estratégicas envolvendo setores de governo, particularmente o Conselho $\mathrm{Nacional}$ dos Direitos das $\mathrm{Mu}$ Iheres, ao lado do M inistério da Saúde e do movimento feminista.

O tema planejamento familiar mostrou-se recorrentenas conferências sobre população em 1974, em Bucareste; 1984, no M éxico eem 1994, no Cairo. N essas conferências, a posição formal do Brasil esteve identificada pela defesa do livre arbítrio das pessoas e dos casais em relação ao número de filhos, desatrelando práticas contraceptivas dos interesses relativos a controle demográfico. A conferência do Cairo, diferente das demais, contou com grande participação da sociedade civil brasileira, especialmente do movimento feminista.

Nas décadas de oitenta en oventa, o debateavança e fortalece a articulação a favor do controle do crescimento da população, desta vez domesticada e inserida no discurso por políticas para os direitos sexuais e reprodutivos e saúde da mulher, a qual transparece no plano de ação resultante da Conferência sobrePopulação e D esenvolvimento, realizada em 1994, no Cairo. A conferência do Cairo teve seu objetivo ampliado para debater o programa de ação relacionado à dimensão demográfica do de senvolvimento sustentável, intensificando o esforço empreendido no Rio de Janeiro, em 1992, na Conferência Mundial do Meio Ambiente. No Rio, foram frustrantes as conquistas relacionadas à definição de políticas de redução do crescimento demográfico tendo sido val orizado, especialmente, os temas do saneamento, da situação socioeconômica mundial e dos desequilíbrios da biosfera¹.

A pressão sofrida pelo Brasil durante a Conferência Mundial sobre o Meio Ambiente, realizada no Rio de Janeiro em 1992, liderada pelos Estados Unidos e integrada por seus parceiros do chamado Primeiro Mundo, introduz uma inovação no argumento neo-malthusiano sobre a necessidade do controle demográfico. Dessa vez, a argumentação se fundamenta na necessidade de garantir a política de controle da fecundidade, em alusão à provável escassez dos recursos naturais, assim como à necessidade deassegurar equilíbrio eproteção ambiental. Essa reconfiguração do debate internacional, com a clara adesão de importantes setores ambientalistas às idéias de controle populacional, ocasionou um mal-estar no movimento feminista, até então clássico aliado dos ambientalistas.

$\mathrm{Se}$, no que diz respeito à aprovação das propostas trazidas para o campo do desenvolvimento, os esforços empreendidos no Cairo pelos países mais ricos foram frustrantes, o mesmo não se pode dizer sobre o debate e seus resultados acerca do tema população. Embora o Cairo tenha emudecido frente a importantes questões demográficas, como o foi no caso do envel hecimento, da mortalidade geral e das migrações ${ }^{1}$, aprofundaram-se as questões de fecundidade e de planejamento familiar, fortalecido, desde então, pela condição de integrante da esfera dos direitos humanos.

A Conferência Internacional sobre População e Desenvolvimento, realizada no Cairo em 1994, define saúde reprodutiva como um estado de completo bem-estar físico, mental e social em todas as matérias concernentes ao sistema reprodutivo, suas funções e processos, e não a simples ausência de doença ou enfermidade (Capítulo VII, parágrafos 7.2). Para o campo da saúde, entretanto, esse conceito é critico em decorrência da fragmentação associada exclusivamente à reprodução que despreza as dimensões da complexidade da saúde integral2 ${ }^{2}$.

$\mathrm{Na}$ celebração dos resultados do Cairo pelos movimentos feministas, não convém desvalorizar os contextos e avanços nacionais em relação ao tema da integral idadecontida no precedente debate e nas formulações de políticas públicas para a saúde das mulheres. A consciência desta fragmentação trouxe a discussão, que se desdobra ao longo dos anos noventa, sobre o conceito de saúde reprodutiva envolvendo os movimentos feministas e diversas organizações internacionais no esforço de tentar articulá-lo com os direitos reprodutivos e sexuais. Esse esforço tem a intenção de estabelecer "um vínculo entre saúde e direitos reprodutivos, em uma perspectiva que integra premissas de desenvolvimento eqüitativo e direitos humanos"3. No Brasil, o Conselho Nacional dos Direitos da Mulher, na Plataforma de Ação de Pe quim, manifesta-se claramente sobre 0 assunto: os direitos humanos das mulheres incluem seu direito a ter controle sobre as questões relativas à sexualidade, incluída sua saúde sexual ereprodutiva, a decidir livremente a respeito dessas questões, sem verem-se sujeitas à coerção, à discriminação ou à violência. 
Não há duvida que, nos anos noventa, a central participação do movimento feminista brasileiro nos processos e nos resultados das conferências do sistema ONU eparalelas, além de sua grande capacidade de articulação com feministas de todos os países, conformou alianças estratégicas que resultaram em inegável acúmulo de poder de intervenção de ativistas nacionais, o que, de certa forma, conferiu ao movimento feminista brasileiro grande respeito no plano internacional.

Saúde materno infantil: relações governo-sociedade

As tentativas do M inistério da Saúde, tanto no caso da incorporação da paternidade responsável ou mesmo na formulação do Programa de Prevenção da Gravidez de Alto Risco na década de setenta, foram eficazmente combatidas pela sociedade brasileira. M ovimentos e lideranças sociais junto com os partidos políticos clandestinos do campo progressista polemizaram as idéias e princípios dos grupos pró-controle demográfico que sustentavam estas iniciativas. 0 argumento estruturante destas forças sociais era 0 avanço das estratégias imperialistas americanas, interessado na baixa densidade demográfica, e a necessidade de ocupação territorial para a defesa da autonomia e soberania nacional.

A fragilidade política com que o M inistério da Saúde enfrentava o tema do planejamento familiar criou um vácuo institucional do Estado, o que favoreceu a ação das instituições de cunho "controlista", queagiam deforma desordenada em todo o território nacional. D entreelas, a Sociedade Civil de Bem-Estar Familiar no Brasil (BEM FAM) e o Centro de Pesquisas de Assistência Integrada à Mulher e à Criança (CPAIM C) foram as de maior relevância 4 .

A BEM FAM, criada em novembro de 1965 como uma entidade privada sem fins lucrativos, tinha sua sede no Rio de Janeiro e foi a primeira instituição a realizar o planejamento familiar no país, atuando em quase todo o território nacional. Filiada à Federação Internacional de Planejamento Familiar (IPPF), foi considerada de utilidade pública a partir de 1971. No início, a ação da BEM FAM foi caracterizada pela criação declínicas de atendimento e distribuição de anticoncepcionais para pobres, em diversos estados. A expansão para centenas de municípios se fez pelo Programa de Distribuição Comunitária de Anticonceptivos, adotado especialmente na região nordeste $e^{5}$. A distribuição de métodos contraceptivos sem critérios e sem o monitoramento clínico constituiu uma si- tuação derisco, ainda hojenão dimensionado, para a saúde das mulheres atendidas pela BEM FAM .

$O$ CPAIM C era financiado pela Agency for International Development (AID), através da Family Planning International Assistance (FPIA), Pathfinder Foundation eoutras, cuja estratégia, mais agressiva e eficaz, foi fundamental na consolidação da ideologia contraceptiva intervencionista no meio médico. Paratanto, financiou treinamentos de profissionais vinculados ao ensino da medicina, da enfermagem e de outras áreas afins, além de sustentar uma verdadeira rede de médicos que atuavam na realização de esterilização cirúrgica via laparoscopia, doando o equipamento e subsidiando as suas atividades. O CPAIM C distribuiu material e insumos contraceptivos para diversas outras instituições congêneres, usando de sua prerrogativa legal de isen ção de impostos para importação como entidade de utilidade pública, sem fins lucrativos ${ }^{6}$. A presença assídua da I greja nesse debate, que persistiu ao longo das décadas de sessenta e setenta, reforçava a sua moral doutrinária que vincula a prática do sexo à procriação. Essa posição foi relativamente flexibilizada no final dos anos setenta, quando a I greja passou a admitir o controle da fecundidade, desde que o método utilizado fosse o da abstinência periódica. Essa flexibilidade para o uso do método denominado pela I greja como natural re presentou importante avanço na modificação das herméticas orientações consagradas no Concílio de Trento, realizado no século XVII.

No endurecimento da ditadura militar brasileira nos anos setenta, reforça-se o discurso da segurança nacional ameaçada pelo grande contingente de pobres e numerosas famílias, "presas fáceis para a propaganda de idéias subversivas". Fica ressaltado, ainda, o recrudescimento de idéias eugênicas expressas, por exemplo, na declaração do General Valdir Vasconcel os, em 1982, sobre a condição de sub-raça de brasileiros que não atingiam as mínimas condições físicas e de saúde exigidas para o ingresso no serviço militar, indicando, segundo ele, a premência de controlar nascimentos desta subespécie.

A radicalização dos militares em relação ao tema da demografia vinculado ao crescimento da população pode ter sido a motivação necessária para o surgimento da indignação de novos atores neste processo do debate. Note-se que, ao longo dos anos setenta, as idéias dos movimentos feministas internacionais eram introduzidas no país conferindo argumentação substantiva ao iniciante feminismo brasileiro.

M anifestando suas preocupações com as muIheres, objeto específico das políticas demográfi- 
cas, as feministas, organizadas em dispersas e frágeis organizações, introduziram no debate posições firmes sobre as suas aspirações, desconstruindo os argumentos em cena e conclamando a autonomia das mulheres na escolha dos seus destinos relacionados à procriação. Com críticas às instituições que atuavam no controle demográfico, as feministas se contrapunham aos argumentos de ocupação do território nacional que mutilavam a autonomia das mulheres ${ }^{7,8}$.

Desde 1960, as brasileiras vinham processando a ruptura com o papel social que lhes era atribuído, introduzindo-se no mercado de trabalho e ampliando suas aspirações de cidadania. Controlar a fecundidade e praticar a anticoncepção passa a ser aspiração das mulheres. A sexualidade plena e os novos padrões de comportamento sexual desvinculam a maternidade do desejo eda vida sexual. Essa conjuntura implicou a necessidade de políticas de acesso aos métodos contraceptivos.

Embora os governos fizessem vistas grossas à ação das instituições de controle demográfico, o país não dispunha de nenhuma política sobre o tema e, portanto, os serviços públicos de saúde estavam despreparados para essa demanda. Os serviços existentes vinculados à BEM FAM ou CPAIMC tinham qualidade duvidosa e ofertavam planejamento familiar dissociado de atenção à saúde, com limitação da disponibilidade aos métodos de alta eficácia. Isso resultava em risco à saúde das mulheres e não permitia a livre escol ha contraceptiva. Esta critica compôs o conjunto das reivindicações feministas.

O cenário ficou cada vez mais complexo, entremeando demandas reais com ideologias: os setores esquerdistas insistiam na soberania nacional ao passo que, na classe média, crescia a demanda pela oportunidade da livre escolha dos métodos contraceptivos, surgindo valores de liberdade pessoal na decisão acerca do número de filhos com emancipação da mulher ${ }^{9}$. Resultado da exclusão social, as classes populares assumem a redução do núme ro de filhos como uma questão de sobrevivência. Esta conjuntura impôs atitudes ao governo e cumpre reconhecer que as fontes inspiradoras destas mudanças nas políticas de saúde da mulher que resultaram no PAISM foram, pela vertente da saúde, o movimento da reforma sanitária e, pela vertente das concepções políticas específicas sobre as mulheres, o então incipientemovimento feminista.

\section{O PAISM : uma política para as mulheres?}

Como resultado desse processo, prevaleceu o dis- curso consensual baseado nos princípios do direito à saúde e na autonomia das mulheres e dos casais sobre a defini ção do tamanho da prole. Esse consenso entregoverno esetores da sociedade civil teve como respaldo, no setor da saúde, o processo avançado da reforma sanitária brasileira no país. Anos mais tarde, o movimento da reforma sanitária contabilizaria sua grande conquista ao inscrever a saúde, na Constituição Federal, como direito do cidadão e dever do Estado.

Em 1983, o M inistério da Saúde cria o Programa de Assistência Integral à Saúde da Mulher (PAISM ), no qual prevalece a análise da complexidade das questões de saúde das mulheres orientando a integralidade da política e ressaltando a autonomia destas sobre questões reprodutivas. 0 PAISM foi apresentado em 21 de junho de 1983, pelo então Ministro da Saúde Valdir Arcoverde, por ocasião de seu depoimento à Comissão Parlamentar de Inquérito que investigava os aspectos do crescimento populacional. Depois de um momento inicial de dúvidas e ataques, o movimento de mulheres passou a defender o PAISM. Em 04/ 01/1986, por meio da Portaria 3.360/86, o Instituto Nacional deAssistência M édica da Previdência Social (INAM PS) define o PAISM como referência para a atenção às mulheres e orienta estratégias de sua implantação, refletindo a conjuntura do trabalho articulado dessa instituição com o M inistério da Saúde por meio das Ações Integradas de Saúde (AIS) ${ }^{10}$.

M ais tarde, a Constitui ção Federal de 1988 institui o Sistema Ú nico de Saúde (SUS) e define o planejamento familiar como de livre arbítrio das pessoas. Abrangendo um conjunto de princípios e diretrizes programáticas, o PAISM contempla as diversas etapas, ciclos de vida e situações de saúde das mulheres, incluindo, naturalmente, os assuntos da reprodução. No que diz respeito ao planejamento familiar, afirma a livre escolha e preconiza que os indivíduos não se submetam a riscos para a saúde em decorrência da procriação e da anticoncepção, garantindo "o direito de todos os segmentos da sociedade à livre escolha dos padrões de reprodução quelhes convenham como indivíduos ou como casais $[\ldots]^{\prime \prime 1}$.

O PAISM esclarece que o planejamento familiar deve incluir ações para a anticoncepção e também atenção aos casos de infertilidade. Com o propósito de garantir autonomia na escolha dos métodos e do controle da fertilidade, são valorizadas as práticas de educação em saúde e sexualidade, entendidas como instrumentos para disseminar as informações e possibilitar capacidade crítica às mulheres para a eleição de métodos. 0 programa 
recomenda ainda quese ofereça o conjunto de tecnologias disponíveis para a anticoncepção e que a atenção ao planejamento familiar seja realizada no contexto da atenção à saúde; portanto, sob as diretrizes do princípio da integralidade da saúde ${ }^{12}$.

$\mathrm{Na}$ esfera do poder legislativo, ressalta-se, entre outras iniciativas, a lei de regulamentação do planejamento familiar em 1996. No plano do executivo, as normas editadas pelo M inistério da Saúde relacionadas ao parto, pré-natal, violência, entre outros, representam reais avanços na operacionalização do PAISM pelo SUS.

No entanto, todo este avanço no plano da legislação ou mesmo das iniciativas do poder executivo não foi suficiente para estabelecer mudanças no padrão de queda da fecundidade no Brasil: fenômeno quese inicia na década de sessenta eque atravessa os anos oitenta e noventa, chegando à virada do século com a média de 2,3 filhos por mulher. A queda da fecundidade é resultado do uso generalizado de contraceptivos de alta efetividade no controle da procriação, como no caso das pílulas e da esterilização cirúrgica, que configuram os métodos mais utilizados ${ }^{13}$. Essa constatação éevidência direta de que o PAISM não modificou a condição da vida reprodutiva das mulheres brasileiras.

A luta pela integralidade da saúde das mulheres

A ebulição política dos movimentos sociais e sindicatos nos anos oitenta, fruto das insatisfações com as condições de vida, e trabalho, e condução política do governo, eclodiram nas greves no final dos anos setenta e nas manifestações de entidades dos movimentos populares e sindicais ao longo dos anos oitenta. $\mathrm{Na}$ conjuntura de transição à democracia, a partir dos anos oitenta, a mobilização dos movimentos sociais, inclusive a do movimento de mulheres, se intensificou.

O fortalecimento dos movimentos de mulheres e a presença de lideranças e setores de mulheres nos partidos políticos permitiu que, em 1985, fossem criados os consel hos nacional eestaduais com a missão de defesa dos direitos da mulher, e implantadas delegacias para mulheres. A participação delideranças feministas nas instâncias relacionadas com a saúde pode ser dimensionada pela ampliação da representação das mulheres na Câmara Federal e poder legislativo de estados e municípios e pela presença de feministas sanitaristas comprometidas com a necessidade de mudanças profundas no sistema de saúde nos fóruns organizados pelos movimentos de mulheres e pelo movi- mento sanitário ${ }^{14}$. As demandas em torno do projeto de reforma sanitária, apresentado e debatido na 8 a Conferência $\mathrm{N}$ acional de Saúde por cerca de 5.000 participantes, em 1986, com forte atuação das mulheres, permitiram o reconhecimento sobre as especificidades do tema saúde da mulher e aprovaram, entre as resoluções da 8 a Conferência N acional de Saúde, a convocação imediata da Conferência Nacional de Saúde e Direitos da Mulher. Refletindo as premissas da 8 a Conferência Nacional de Saúde, a Conferência Nacional de Saúde e Direitos da Mulher, organizada também em 1986 pelo Conselho Nacional deDireitos da M ulher, com 0 apoio dos movimentos de mulheres de todo 0 Brasil, do M inistério da Saúde eM inistério da Previdência, reafirmou e detalhou as diretrizes norteadoras das políticas de saúde da mulher sintonizadas com o PAISM, transformando-as em resoluções programáticas. 0 Quadro 1, contendo uma seleção reduzida dessas resoluções formuladas por cerca de 900 participantes, ilustra a riqueza do debate e das perspectivas de mudanças na organização da atenção à saúde da mulher.

As resoluções da Conferência Nacional deSaúde e Direitos da Mulher foram transformadas em instrumento político, "Carta das mulheres brasileiras aos constituintes", e neste documento, a saúde reafirma-se como tema central da agenda dos movimentos de mulheres. A carta continha duas premissas: a de que saúde era um direito de todos e dever do Estado e que a mulher tinha o direito à atenção a sua saúde, independente do seu papel de mãe.

Lutava-se pelos princípios de atenção integral à saúde da mulher e enfatizava-se a oposição à coerção de entidades públicas ou privadas, nacionais ou internacionais, impondo ou negando 0 acesso aos meios de regulação da fecundidade ${ }^{15}$.

A Constituição de 1988 analisou mais de 120 propostas e emendas substitutivas encaminhadas pelos movimentos de mulheres ao Congresso $\mathrm{Na}$ cional. Dos embates do movimento feminista com as correntes conservadoras no processo constituinte, o texto constitucional registra um inequívoco avanço ao situar o planejamento familiar na esfera dos direitos "Da Família, da Criança, do Adolescente e do Idoso". De acordo com o artigo 226 parágrafo 70: [...] o planejamento familiar élivre decisão do casal, competindo ao Estado propiciar recursos educacionais e científicos para o exercício desse direito e vedada qualquer forma coercitiva por parte de instituições oficiais e privadas ${ }^{16}$.

Outro ponto positivo, na avaliação dos estudiosos dos direitos da mulher quanto na dos pesquisadores do movimento sanitário, é a ausência, no 
texto constitucional, de uma proposição apresentada pela I greja Católica e por setores evangélicos relativa à defesa da vida desde a concepção. A inclusão desta proposição representaria um retrocesso.

0 aborto [...] não foi incluído nem restritivamente e nem de forma facilitadora [...]. Embora tenha havido pressões eemendas para ampliar as possibilidades do abortamento estas não tiveram acolhida. M as tampouco a redação de uma das versões do Relatório da Comissão da O rdem Social que o vetava radicalmente teve condições de aprovaçãa ${ }^{17}$.

Das vitórias do movimento sanitário, no que se refere à consagração da saúde como direito univer- sal edever do Estado edo movimento feminista em ver respeitada uma plataforma mínima de mudanças nas concepções sobre o papel da mulher, decorreram mudanças radicais, ainda que no plano formal, nas acepções sobre saúde e sobre saúde da mulher. A ampliação do conceito de saúdepara além do acesso à assistência médico-hospitalar subjacenteà criação do Sistema de SeguridadeSocial eda extensão das fronteiras da saúde da mulher para latitudes elongitudes, nas quais o confinamento da mulher à condição de reprodutora torna-se superado, instalam uma nova ordem nas relações entre Estado, governo e sociedade.

Quadro 1. Resoluções selecionadas* da Conferência Nacional de Saúde e Direitos da Mulher, 1986.

\begin{tabular}{|c|c|}
\hline Temas & Resoluções selecionadas \\
\hline $\begin{array}{l}\text { Assistência integral à saúde } \\
\text { da mulher na perspectiva } \\
\text { de consolidação do } \\
\text { Sistema Único de Saúde }\end{array}$ & $\begin{array}{l}\text { Res. 4. A criação do sistema único de saúde coloca um grande desafio para } \\
\text { a soci edade em geral e para os técnicos do setor em particular. Com } \\
\text { respeito à mulher, enquanto cidadã e usuária dos serviços de saúde, coloca } \\
\text { igualmente o desafio de como inserir as questões específicas de sua } \\
\text { identidade e sua saúde no sistema único de saúde e de como efetivar o } \\
\text { controle social da população feminina sobre o processo da reforma } \\
\text { sanitária, a fim de assegurar seus direitos. } \\
\text { Res. 11. Reforçar o PAISM } \\
\text { Res. 13. A política de Assistência Integral à Saúde da M ulher deverá } \\
\text { assumir, progressivamente, a plena implantação do planejamento familiar, } \\
\text { em todos os seus aspectos, de forma que as entidades privadas controlistas } \\
\text { sejam desativadas. } \\
\text { Res. 14. Capacitação do setor público na produção de medicamentos e } \\
\text { tecnologia em saúde, estimulando a pesquisa de acordo com as } \\
\text { necessidades do PAISM. }\end{array}$ \\
\hline Direitos reprodutivos & $\begin{array}{l}\text { Res.4. O atendimento à anticoncepção obedecerá aos seguintes critérios: } \\
\text { respeito à liberdade de escolha; acesso a todos os métodos existentes, com } \\
\text { orientação quanto a cada um deles; critérios de avaliação clínica e } \\
\text { acompanhamento pelos serviços de saúde, antes, durante e depois do seu } \\
\text { uso. } \\
\text { Res. 8. As ações de concepção e contracepção não serão atividades isoladas, } \\
\text { devendo ser assumidas e geridas pelo Estado, através de seus órgãos de } \\
\text { saúde, com a participação do movimento de mulheres, sem a ingerência de } \\
\text { interesses privados nacionais ou multinacionais. }\end{array}$ \\
\hline Aborto & $\begin{array}{l}\text { Legalizar o aborto, já que o mesmo nas condições em que atualmente } \\
\text { ocorre no Brasil constitui um problema de saúde pública e saúde mental; e } \\
\text { propiciar assistência e condições para que a mulher que decida fazê-lo o } \\
\text { faça de forma consciente, sendo-Ihe garantida assistência médica e } \\
\text { psicológica. O aborto não deve ser considerado como um método } \\
\text { contraceptivo, sendo por isso fundamental que seja dado à sociedade o } \\
\text { conhecimento dos métodos contraceptivos existentes, visando que o } \\
\text { aborto seja uma prática cada vez mais reduzida. }\end{array}$ \\
\hline
\end{tabular}

* As resoluções selecionadas referem-se a temas aprovados integralmente.

Fonte: Relatório final da Conferência Nacional deSaúdee Direitos da M ulher, 10 a 13 de outubro de 1986. 
O SUS nos anos noventa e a saúde da mulher: avanços edilemas

No quadro recessivo dos anos noventa, o ajuste fiscal passou a ditar os rumos da política brasileira. A subordinação dos problemas sociais à lógica economicista afetou a organização dos movimentos sociais. A fragmentação das políticas sociais, embora concomitante ao estímulo à participação das entidades populares em conferências e conselhos setoriaisque pretendem mediar a interlocução da sociedade com o poder público, refletiu-se na pulverização das demandas pela conquista de cidadania.

0 movimento de mulheres, tal como o sanitário, passou a resistir às pressões e restrições e a buscar avançar proposições para a efetivação do PAISM . Ao tempo que amplia o engajamento dos movimentos sociais envolvidos na luta pela saúde das mulheres às idéias proclamadas pelo PAISM , 0 movimento feminista passa a se instituir fundamentalmente em organizações não governamentais, profissionalizando a sua atuação militante. Assim é que entidades do movimento feminista passam a atuar, de forma profissional, como parceiras do Ministério da Saúde na produção de materiais educativos e técnico normativos para a aten ção e o cuidado à saúde das mulheres. Pode-se afirmar que as feministas não priorizaram nos anos oitenta e noventa a atuação nas instâncias estaduais emunicipais de participação e decontrole social da saúde das mulheres. Em um contexto específico, o então M inistro daSaúde, Adib J atene, nomeou como conselheira do Conselho $\mathrm{Nacional}$ de Saúde uma feminista, M argareth Arilha, para ocupar uma das vagas destinadas à sociedade científica. Essa iniciativa foi importante por ter permitido a vocalização das demandas das mulheres e o surgimento de novos posicionamentos políticos naquele órgão colegiado.

Já nos estados e municípios, constata-se, nesse período, um vazio absoluto de representações de movimentos de mulheres nos respectivos conseIhos de saúde, particularmente de feministas. Isso, no entanto, não impediu que esses movimentos, mesmo concentrados territorialmente em poucos estados, desenvolvessem um importante e qualificado trabalho participativo junto às instituições de saúde, demandando a implantação de ações de saúde sintonizadas com o PAISM ${ }^{4}$. A rearticulação da organização das mulheres e da retomada do tema saúde da mulher na agenda governamental só ocorreu a partir de 1995, como reflexo da Conferência do Cairo realizada em $19944^{18}$. De fato, no âmbito interno, a mobilização de mulheres readquire visibilidade com o fortalecimento das mu-
Iheres rurais ( $M$ archa das $M$ argaridas); a articulação das mulheres negras; as redes de mulheres soropositivas; os movimentos pelo reconhecimento dos direitos sexuais das mulheres lésbicas, entre outros. Porém, a agenda de direitos da mulher retorna ao status de prerrogativa da sociedade civil. As tentativas de apropriação dos espaços governamentais durante o mandato do presidente Fernando $\mathrm{H}$ enrique não foram muito eficazes. $\mathrm{O}$ CNDM continuou a ser um órgão de caráter deliberativo subordinado ao Ministério da Justiça ${ }^{19}$.

É a internacionalização das agendas dos movimentos de mulheres que repõe o tema na pauta governamental. Porém, a absorção das questões da fecundidade e do planejamento familiar pelo conceito desaúde reprodutiva deslocou a centralidade da saúde integral da pauta das políticas de saúde para as mulheres. Para autores como Lassonde ${ }^{1}$, a adoção e difusão do conceito de saúde reprodutiva conecta-secom a influência das políticas demográficas ditadas pelos países centrais aos países periféricos, com a vantagem da adesão de setores anteriormente críticos a essa conexão. No caso brasileiro, trata-se também de abandonar avanços já conquistados na advocacia pautada na abordagem mais ampliada do reconhecimento das verdadeiras dimensões e complexidades da saúde das mulheres.

A conjugação das tendências que marcaram os anos noventa está relacionada às restrições na interlocução dos movimentos de mulheres com o governo por meio Conselho Nacional de Direitos da M ulher, aos limites à implementação do SUS, à forte ênfase nos programas de saúde fragmentados e às pressões emanadas do alargamento do intercâmbio internacional pela adoção depolíticas de planejamento familiar. As denúncias sobre a esterilização de mulheres negras no Brasil que foram apuradas na Comissão Parlamentar M ista de inquérito instalada em 1991 reforçou a necessidade de regulamentar a Constituição de 1988 sobreo tema, contribuindo com a primeira versão de projeto que mais tarde resultou na Lei 9.263 de 1996. Esta lei regulamenta o planejamento familiar eatribuiu ao SU S as responsabilidades pela execução de ações de regulação da fecundidade voltadas à garantia de direitos iguais de constituição, limitação ou aumento da prole pela mulher, pelo homem ou pelo casal. O PAISM , tomado como referência para a elaboração desta lei, contribuiu para reafirmar a inserção do planejamento familiar entre as ações de saúde destinadas à atenção integral à saúde da mulher em todos os seus ciclos vitais e reforçou 0 componente emancipatório da mulher quanto às decisões em saúde. Em seu artigo 4ํㅜ, a lei 9.263 
propõe que o planejamento familiar se oriente por ações preventivas e educativas e pela garantia de acesso igualitário a informações, meios, métodos e técnicas disponíveis para a regulação da fecundidade $^{18}$. Para Correa e Piola ${ }^{20}$, o nível federal de administração apresentou, na dé-cada de noventa, dificuldades e descontinuidade no processo de assessoria eapoio para implementação do PAISM . Contraditoriamente, o M inistério da Saúde priorizou a saúde da mulher partir de 1998, mas adotou como estratégia reforçar apenas ações relacionadas ao pré natal, assistência ao parto e à anticoncepção, limitando assim a atenção integral da saúde da mulher à dimensão reprodutiva. Para 0 câncer cérvico uterino, adotou a questionável estratégia de campanhas de real ização de exames diagnósticos. A oferta de serviços para a realização de exames preventivos para câncer ginecológico deve ser permanente eamplamente disseminada na rede e esta campanha, sem fixar a atividadena rede SUS e sem preocupações com a retaguarda para 0 casos suspeitos identificados, acabou por deixar um saldo eticamente complicado. Muitas entidades e organizações feministas emprestaram seu prestígio e mesmo sua capacidade técnica a estas iniciativas ministeriais.

Constata-se que, se o PAISM permanece como norteador das ações no nível teórico, na prática ele não resistiu à fragmentação em programas por agravo ou condição que foram e são sucessivamente criados. Por outro lado, se esta fragmentação é fato, observa-se também que no momento atual há uma clara difusão de responsabilidades entres os diversos órgãos e áreas do M inistério da Saúde por atuar em saúde das mulheres e isso quer dizer que o tema se tornou transversal.

No entanto, na prática, ainda existe toda sorte de problemas que impedem que as mulheres sintam mudanças concretas na rede de serviços do SUS. Destacam-se nesse contexto as grandes desigualdades de oferta, assim como as ações relacionadas ao climatério/menopausa; às queixas ginecológicas; à infertilidade e reprodução assistida; à saúde da mulher na adolescência; a doenças crônico-degenerativas; à saúde ocupacional; à saúde mental; a doenças infecto-contagiosas.

Ainda que o balanço das políticas de saúde das mulheres nos anos noventa não contabilize grandes avanços no que se refere à atenção integral à saúde das mulheres, éimprescindível assinalar dois movimentos significativos, que indireta ou diretamente alteraram o panorama institucional das ações direcionadas à saúde das mulheres. 0 pri- meiro refere-se à expansão das coberturas de atenção básica a toda população brasileira, decorrente da universalização do acesso e ampliação da oferta de serviços de saúde de base municipal com a estratégia do Programa de Saúde da Família. E o segundo diz respeito aos processos de mudança nos modelos deatenção às mulheres, especialmenterepresentados por iniciativas voltadas à redução das taxas de cesárea e à humanização do parto.

\section{A situação atual da participação social das mulheres por saúde}

Informações preliminares do Sistema Nacional de Informações sobre Consel hos e Consel heiros de Saúde- ParticipanetSU S - dão conta que, em 2007, entre 5.463 conselhos municipais de saúde, existem 276.542 entidades representando os usuários do SUS. Dessas, apenas 623 , ou seja, 0,23\%, são relacionadas à temática das mulheres. Dentre estas 623 entidades, observa-se que mais da metade delas (54,57\%) são clubes ou associações demães, $26,48 \%$ são de movimentos sociais de mulheres, 8,19\% são sindicais e o restante, de outras modalidades.

A representação dos movimentos de mulheres está presenteno Conselho N acional deSaúde(CNS) não apenas por meio da entidade representativa do respectivo movimento como também as representações de população negra, população LGBT, população do campo, sindicalistas e outros que conformam uma configuração favorável aos avanços nas questões de saúde das mulheres e seus direitos sexuais e reprodutivos. A Comissão Interinstitucional de Saúde da Mulher (CISMU), instância de assessoramento ao pleno do CNS, tem ampla presença de setores representados e mantém uma regularidade de debates e de contribuições.

É rara a presença da temática da saúde da mulher nas pautas e nos debates do CNS que foram estudados por meio dos registros nas atas de reuniões ordinárias e extraordinárias do colegiado. A Tabela 1 mostra as pautas sobre saúde das mulheres constantes das atas de reuniões realizadas no período de 2003 a 2007. Das 45 vezes que o tema foi objeto de pauta do CNS, por seis vezes (13,3\%) envolveu o debate ea aprovação de políticas e programas para as mulheres; oito $(17,7 \%)$ vezes tratou do tema de avaliação e monitoramento depolíticas eprogramas; eem cinco $(11,11)$ destes eventos o debate foi realizado acerca de situações críticas envolvendo posicionamento ético-político do referido colegiado. 
Tabela 1. Número de debates realizados pelo Conselho Nacional de Saúde com o tema saúde da mulher por categoria: 2003 a 2007.

\begin{tabular}{lcc}
\hline \multirow{2}{*}{ Categoria } & \multicolumn{2}{c}{ Número de debates com o tema saúde da mulher } \\
\cline { 2 - 3 } & Número absoluto & $\%$ \\
\hline Debate e aprovação de políticas e programas & 6 & 13,33 \\
Avaliação/monitoramento de políticas e programas & 8 & 17,77 \\
Debate e posicionamento sobre situações críticas & 5 & 11,11 \\
Informes e indicações de representações do CNS & 26 & 57,77 \\
Total & 45 & 100 \\
\hline
\end{tabular}

Fonte: Atas do CN S2003-2007.

A avaliação dos problemas da saúde da muIher e as demandas pela plena efetivação do SUS e do PAISM retornam à pauta do movimento feminista por ocasião da I Conferência Nacional de Políticas para Mulheres realizada em 2004 - Ano da Mulher - contando com a participação de cerca de 1.800 delegadas. $\mathrm{Na}$ esfera setorial, a $12^{2}$ Conferência Nacional de Saúde, realizada em 2003, que teve como tema: "Saúde: um direito de todos eum dever do Estado. A saúde que temos, o SUS que queremos", produziu um relatório que também recomenda no sub-tema "Saúde e Gênero" o avanço na implementação da Atenção Integral à Saúde da Mulher (PAISM ), além de alertar para a necessidade de considerar as especificidades, tais como das mulheres negras, lésbicas, profissionais do sexo eindígenas.

Sensível ao debate, o M inistério da Saúde lançou a Política Integral à Saúde da M ulher, proposta que busca retomar as proposições do PAISM, atualizando-as e adequando-as às necessidades presentes nos últimos vinte anos. O Plano Nacional de Saúde (PNS), Um Pacto pela Saúde do Brasil (2005), aprovado pela Portaria 2.607, de 10 de dezembro de 2004, teve como referência as deliberações da $12^{\text {a }}$ CNS realizada em dezembro de 2003 e o Plano Plurianual - PPA. Este instrumento de referência é indispensável à atuação das esferas de direção do SUS, pois tem o objetivo de contribuir para a redução das desigualdades e iniquidades em saúde, mediante pactos de metas estratégicas para a melhoria das condições de saúde da população e para a resolubilidade do SUS. O plano contempla, dentre as iniciativas prioritárias do M inistério da Saúde, a saúde da mulher e estabelece como metas:

- Reduzir em $15 \%$ os índices de mortalidade materna;
. Aumentar em $50 \%$ o número de serviços de saúde do SUS para a realização de laqueadura tubária e vasectomia em todos os estados;

. Reduzir em $15 \%$ a taxa nacional de cesariana no SUS;

. Aumentar em $30 \%$ os serviços de atenção às mulheres em situação de violência nos municípios pólos de microrregiões;

- Aumentar em $15 \%$ a cobertura do exame Papanicolau na população de risco ( 35 a 49 anos de idade);

- Aumentar em $25 \%$ a realização de cirurgias para reconstrução mamária;

- Reduzir em $15 \%$ o número de complicações de aborto no âmbito do SUS;

. Implantar comitês demortematerna em 100\% dos municípios com população superior a $50 \mathrm{mil}$ habitantes;

- Reduzir em 6\% a incidência de aids em muIheres;

- Alcançar $100 \%$ de cobertura com a vacina dupla adulto em mulheres em idade fértil de 15 a 49 anos deidade, nas regiões $N$ orte, N ordeste, norte de M inas Gerais e no estado de Goiás, correspondendo a 2.288 municípios, com vistas à proteção da mãe e do concepto contra o tétano acidental e neonatal;

- Implantar/implementar cinco centros de referência para atendimento à fertilização de casais sorodiferentes para o HIV;

- Garantir a pelo menos $60 \%$ das gestantes integrantes das famílias beneficiárias do Programa Bolsa Família o acompanhamento segundo a agenda de compromissos do setor saúde (vigilância al imentar e nutricional, vacinação e pré natal).

O plano de ação busca consolidar os avanços no campo dos direitos sexuais e direitos reprodutivos, com ênfase na melhoria da atenção obstétri- 
ca, no planejamento familiar, na atenção ao abortamento e no combate à violência doméstica e sexual. Agrega a preven ção e 0 tratamento das DSTs, a atenção às mulheres vivendo com HIV/ aids e às portadoras de doenças crônico-degenerativas e câncer ginecológico ${ }^{21}$.

Todas as metas deste plano necessitam ajustes locais para darem conta das diversidades eespecificidades das mulheres brasileiras. É o caso das mulheres negras, das lésbicas, das indígenas, das ciganas, dentre outras. Orientação sexual, etnia, raça, classe social e local de moradia são variáveis que incidem diretamente sobre a saúde e condições de vida. É por isso que, com agenda fixa anual, milhares de mulheres do campo, as M argaridas, ocupam a Esplanada dos M inistérios e negociam com cada se tor suas pautas e reivindicações. N ote-se que estas entidades rurais, especial mentea Confederação dos Trabal hadores da Agricultura (CONTAG) e as vinculadas ao Movimento Sem Terra (MST), desenvolvem importantes projetos cujas finalidades visam ao fortalecimento político de lideranças femininas na atuação pela garantia do direito a saúde.

Dezenas de conferências nacionais setoriais foram realizadas ao longo dos dois mandatos do atual governo e, invariavel mente, todas elas apontam reivindicações e deliberações das mulheres. Entretanto, não há um balanço disponível de monitoramento sobre o grau de atendimento destas demandas, mas é certo que, se comparados os diversos relatórios das distintas conferencias setoriais, observam-se frequentes repetições de reivindicações que muitas vezes reforçam umas as outras, mas que também são contraditórias entre si.

A força política acumulada pelos movimentos sociais nos últimos anos no país não pode ser analisada distanciada do contexto dos macro-cenários. As consequências sociais do cenário dos anos noventa que inaugurou a retirada estratégica do Estado foram 0 acirramento das desigualdades e 0 aumento do desemprego. No plano político, as di- ficuldades do diálogo com a sociedade civil justificaram a fragilização de mecanismos de interlocução entre Estado e sociedade. 0 governo atual tem dado provas de disposição ao diálogo e reconhecimento político dos movimentos sociais e da sociedadecivil; no entanto, análisesfuturas sobre as consequências destas relações necessitam ser realizadas. A presença de inúmeros dirigentes governamentais provenientes dos movimentos sociais gerou, muitas vezes, uma ausência de del imitação de compromissos e de papéis sociais que promiscuem, ou seja, confundem as relações sociedade civil e governo.

Claro é que os processos participativos são ferramentas poderosas na garantia de direitos. Para tanto, énecessário seguir a trilha da politização permanente da sociedade civil e, ao mesmo tempo, permitir soluções criativas de transformação da sociedade movidas pelos interesses coletivos, pela justiça social epela cidadania. Oxalá os novos feminismos oriundos destes novos tempos e matizes tragam força à luta pela saúde das mulheres. A saúde das mulheres deve ser concebida val orizando a perspectiva de classe social e de gênero na determinação social da saúde e, desta visão complexa e ampliada, retomar a necessária articulação da saúde com as políticas sociais, incluindo as de seguridade social, para produzir mudanças efetivas na inclusão e no bem-estar social desta população.

A tentativa nesta abordagem foi mostrar a presença da participação das mulheres na luta pela saúde equanto o percurso dos últimos vinte anos acumulou, apontando numerosos avanços. A marca é da insistente presença da sociedade civil, entendida como uma esfera social distinta do Estado e do mercado, abarrotada de mulheres, cidadãs, associações e movimentos sociais que problematizam novas questões, praticam o advocacy, disputam seus direitos e buscam ampliar a participação e a incidência pública nos processos políticos, desafiando até mesmo os limites da política institucional. 


\section{Referências}

1. Lassonde L. Los desafios de la demografía. ique calidad de vida habrá en el siglo XXI? M éxico: Fondo de Cultura Econômica/UAM ; 1997. p. 52.

2. Costa AM, Aquino E. Saúde da mulher na reforma sanitária brasileira. In: Costa AM, M erchan E,Tajer $D$, organizadores. Saúde, equidade e gênero: um desafio para as políticas públicas. Brasília: UnB; 2000. p. 199.

3. Correa S. "Saúde reprodutiva", gênero e sexualidade: legitimação e novas interrogações. In: Giffin K, Costa SH, organizadores. Questões da saúde reprodutiva. Rio de Janeiro: Fiocruz; 1999. p. 40.

4. Fonseca e Sobrinho D. Estado e população: uma história do planejamento familiar no Brasil. Rio de Janeiro: CEDEPLAR/Rosa dos Tempos; 1993. p. 137.

5. Pêgo RA, Richa AC. Estado e instituições de planejamento familiar. In: Guertechim I, organizador. Controle da natalidade $x$ planejamento familiar no Brasil. Rio de Janeiro: Achiamé; 1987. p. 32.

6. Brasil. Congresso Nacional. Relatório final da Comissão Parlamentar M ista de Inquérito Destinada a Examinar a Incidência de Esterilização em massa de MuIheres no Brasil. Brasília. Centro Gráfico do Senado Federal. Brasília: Congresso Nacional; 1993.

7. Costa AM. PAISM : uma política de assistência integral à saúde da mulher a ser resgatada. São Paulo: Comissão de Cidadania e Reprodução; 1992.

8. Costa AM. Atenção integral à saúde das mulheres: QU 0 VADIS? U ma avaliação da integralidade na atenção à saúde das mulheres no Brasil [tese]. Brasília (DF): Universidade de Brasília; 2004.

9. Guertechin TL. O controle da natalidade: uma questão demográfica e/ou um problema político. In: Guertechin TL, organizador. Controle da natalidade $x$ Planejamento familiar no Brasil. Rio de Janeiro: Achiamé; 1987. p. 28.

10. Costa AM. Desenvolvimento e Implantação do PAISM no Brasil. In: Giffin K, Costa SH organizadores. Questões de saúde reprodutiva. Rio de Janeiro: Fiocruz; 1999.

11. Brasil. Ministério da Saúde. Assistência Integral à Saúde da Mulher: bases de ação programática. Brasília: Ministério da Saúde/Centro de Documentação; 1984. p. 15.

12. Costa AM . O Programa de Assistência Integral a Saúde da Mulher: anotações para um debate. Anais ABEP, 1986. [acessado 2009 abril 05]. Disponível em: http:/ /www.abep.nepo.unicamp.br/docs/anais/pdf/1986/ T86V 02A24.pdf
13. Berquó E. Brasil, um caso exemplar: anticoncepção e parto cirúrgico - à espera de uma ação exemplar. Revista Estudos Feministas 1993; 1(5):366-381.

14. Costa AM, Bahia L, Conte D. A Saúde da Mulher e o SUS: Iaços e diversidades no processo de formulação, implantação e avaliação das políticas de saúde para as mulheres no Brasil. Revista Saúde em Debate 2007; 31(75/76/77):13-24

15. Pitanguy J. O movimento nacional e internacional de direitos reprodutivos. In: Giffin K, Costa SH, organizadores. Questões de saúde reprodutiva. Rio de Janeiro: Fiocruz; 1999.

16. Brasil. Constituição da República Federativa do Brasil. Brasília: Presidência da República; 1988.

17. Rodriguez N eto E. Saúde: promessas e limites da Constituição. In: Rodrigues Neto E, Temporão JG, Escorel $S$, organizadores. Saúde: promessas e limites da Constituição. Rio de Janeiro: Fiocruz; 2003. p. 122.

18. Villela W, Monteiro $S$. Atenção à saúde das mulheres: historicizando conceitos e práticas. In: Villela W, M onteiro S, organizadores. Gênero e Saúde: Programa Saúde da Família em questão. Rio de Janeiro: ABRASCO; Brasília: UNFPA; 2005. p. 15-31.

19. Pitanguy J. Análise da realidade brasileira, avaliando as políticas realizadas e os compromissos assumidos pelo Estado brasileiro. In: Anais da I Conferência Nacional de Políticas para as Mulheres. Secretaria Especial de Saúde para as M ulheres. Brasília. 2004.

20. Correa SO, Piola SF. Balanço 1998-2002: aspectos estratégicos, programáticos e financeiros. Brasília: M inistério da Saúde; 2002. [M imeo]

21. Brasil. Ministério da Saúde. Secretaria de Atenção à Saúde. Departamento de Ações Programáticas Estratégicas. Política nacional de atenção integral à saúde da mulher: plano de ação 2004-2007. Brasília: Ministério da Saúde; 2004.

Artigo apresentado em 01/12/2008

Aprovado em 11/02/09

Versão final apresentada em 07/05/09 